\title{
An Optimization of $(Q, r)$ Inventory Policy Based on Health Care Apparel Products with Compound Poisson Demands
}

\author{
An Pan, ${ }^{1}$ Chi-Leung Hui, ${ }^{2}$ and Frency $\mathrm{Ng}^{2}$ \\ ${ }^{1}$ Institute of Business Administration, Shanghai Finance University, Shanghai 201209, China \\ ${ }^{2}$ Business Division, Institute of Textiles and Clothing, The Hong Kong Polytechnic University, Hung Hom, Kowloon, Hong Kong \\ Correspondence should be addressed to An Pan; missanan@sina.com
}

Received 28 January 2014; Revised 20 April 2014; Accepted 17 June 2014; Published 28 September 2014

Academic Editor: Pui-Sze Chow

Copyright (c) 2014 An Pan et al. This is an open access article distributed under the Creative Commons Attribution License, which permits unrestricted use, distribution, and reproduction in any medium, provided the original work is properly cited.

\begin{abstract}
Addressing the problems of a health care center which produces tailor-made clothes for specific people, the paper proposes a single product continuous review model and establishes an optimal policy for the center based on $(Q, r)$ control policy to minimize expected average cost on an order cycle. A generic mathematical model to compute cost on real-time inventory level is developed to generate optimal order quantity under stochastic stock variation. The customer demands are described as compound Poisson process. Comparisons on cost between optimization method and experience-based decision on $Q$ are made through numerical studies conducted for the inventory system of the center.
\end{abstract}

\section{Introduction}

The research starts from the case study of the health care center, a nonprofit organization which provides tailor-made apparel making services for the disabled and the old. With small-sized inventory capacity, the center cannot have too much cloth material in stock. Due to limited funding, it is necessary to reduce operation cost including inventory cost. Customer orders are stochastic with random arrivals.

From the case study, we summarize the problem as a single item continuous review system with limited inventory capacity and stochastic customer demands. With continuous review, we adopt classic $(Q, r)$ policy as the inventory control policy: when the inventory position (stock on hand plus stock on order minus backorders) reaches the order point $r$, an order is placed for the fixed amount $Q$, the batch size. In this paper, the problem is to determine optimal $Q$ in the objective of minimization of average cost including purchase cost and delivery cost which are classic terms defined by Hadley and Whitin [1].

For stochastic inventory system, $(Q, r)$ policy is the most widely used. There has been no straight-forward solution for computing $(Q, r)$ policy since Federgruen and Zheng [2] propose a simple and efficient algorithm for determination of an optimal $(Q, r)$ policy. The algorithm is based on the observation of long-run average cost. Later Forsberg [3] shows how to exactly evaluate holding and shortage costs for a two-level inventory system with one warehouse and $N$ different retailers. To implement such policy, the system needs the inventory space that can store $(Q, r)$. However, in real practice, the storage space is usually limited due to high cost of land acquisition. Other research on the singleitem $(Q, r)$ policy includes Hadley and Whitin [1], Lau et al. [4], Zheng [5], and the references cited therein. The issue we consider in this paper is important in the following aspects. Firstly, based on standard method, the model is optimized under the restriction of storage space. Although $(Q, r)$ inventory problems have been studied and solved, the effort required to find better plans for problems in different cases and backgrounds may vary considerably. Secondly, to the author's knowledge, little attention has been given on the issue of space constraint in literature. Some research have been made for limit production capacity (see [6-9]). Others have dealt with resource constraint problems for newsvendor models (see $[10,11])$. Thirdly, also based on author's knowledge, there have been few even no intuitive expressions for a space-limited inventory system. Procedures for determining 
optimal $Q$ for most $(Q, r)$ models are to solve iteratively (see [12]). The method is complicated in real execution. In Lau et al., 2002, easy-to-use expressions are presented for computing the exact "average on-hand inventory" level for a variety of lead-time-demand distribution forms. However, the expression of $Q$ is not applicable in minimizing long-run average system cost. Thus, in our paper, we generate methods not only helpful for academic analysis but reasonable and simple enough for business practitioner's execution. Last, we propose the inventory model with infinitesimal method to compute cost on real-time inventory level and assume customer demands as compound Poisson process.

The rest of the paper is organized as follows. In Section 2, we provide related literature of previous research on $(Q, r)$ model in stochastic environment. Section 3 mainly describes the notation and preliminary studies. Detailed model formulation and derivations are also provided in Section 3. In Section 4, case based numerical analysis is conducted and comparisons are made. Concluding remarks and potential future studies are given in Section 5.

\section{Literature Review}

An inventory control system tells us how much to order and when to place the order. To propose a reasonable inventory control system improves operation efficiency. Hence, it brings about advantages like cost-saving, profit earning, and customer satisfaction. Under continuous review, businesses typically track inventory until it reaches a predetermined point of "low" holdings, whereupon an order is made to push holdings back up to a desirable level. $(Q, r)$ continuous review control policies are mostly used for uncertain demand and lead time.

For stochastic models, the continuous review model can be classified according to whether the demands are discrete or continuous. In the case of discrete demands, Poisson demands in the continuous review models are studied in depth [13]. Song and Zipkin [14] consider the case of Markov modulated Poisson demands, while Browne and Zipkin [15] study a model with continuous demand driven by a Markov process. In our research, we discuss, respectively, the optimal $(Q, r)$ inventory models in continuous demand and discrete demand.

Though different inventory systems are proposed for stochastic situation (see [15-20]), $(Q, r)$ control policies are popular for uncertain demand or random lead time in multiperiod. Song et al. [21] discuss the effect of lead time and uncertain demand in $(Q, r)$ policy. Berk and Gürler [22] show a continuous review $(Q, r)$ policy is reasonable good for a perishable inventory system with fixed shelf lives and study the operating characteristics of the system.

Exact analysis and cost evaluation on continuous review installation stock $(Q, r)$ policy for identical or nonidentical retailers are presented, but with the restriction of items in low demand which is depicted by Poisson or compound Poisson (see e.g., [3, 23-25]). A simple heuristic algorithm is proposed to find an approximate near-optimal $(Q, r)$ policy

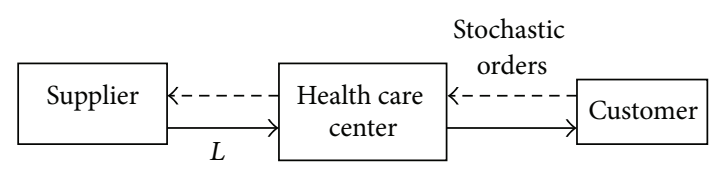

FIGURE 1: System description.

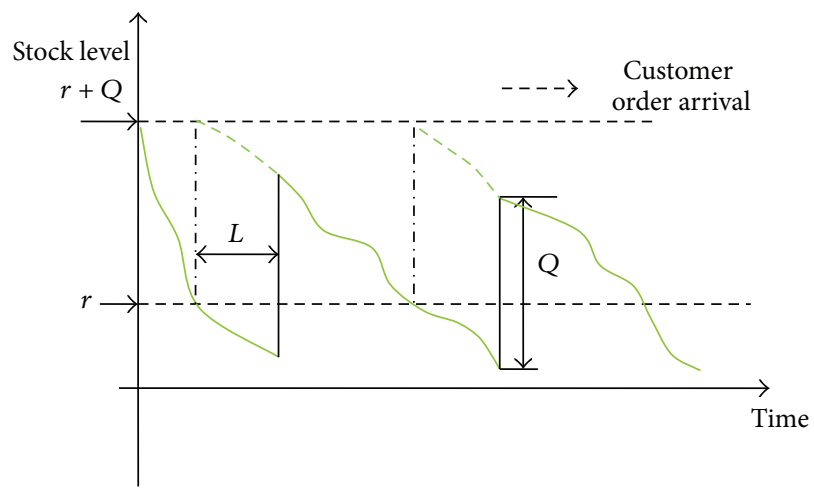

Figure 2: Inventory under $(Q, r)$ policy.

[26]. Heuristic solutions have also been presented to $(Q, r)$ policy (see $[27,28])$.

The methods which previous research provide are elaborate and brilliant; however, these algorithms are not easy to execute. This brings out an important aspect as pointed out by Alstrøm [29]; that is, in view of the evidence from a number of studies showing that firms' use of statistical inventory control lags far behind academic interest in the area. The determination of optimal values for the control variables, even in a very simple inventory control system, is a complex task and therefore not suited to practical implementation. Thus, we hope to find a solution easy to carry out for practical inventory control and meaningful to academic research. Reviewing on the research, in the next section we will formulate the problem and produce efficient solutions for $(Q, r)$ inventory policies.

\section{Optimization Model}

3.1. Overview and Preliminary. The mathematical model is built in the context of a three-echelon supply chain with customer, the health care center, and supplier (see Figure 1). The health care center provides tailor-made clothes for the disabled or the old. Customer demands are depicted as compound Poisson process. It is a single item inventory system with purchase cost fixed. As profit is not first consideration for the health care center, the model aims to minimize average cost in an order cycle. The inventory is reviewed by $(Q, r)$ policy continuously (see Figure 2). Lead time is constant. Two optimal policies are proposed for the inventory model. (1) $r$ is determined by service level so that the safety stock is kept at a reasonable level. Optimal $Q$ is expressed through derivation. (2) Genetic algorithm is developed to derive $r$ and $Q$. We discuss the system in steady state. Demands that cannot be fulfilled in current state are backordered. 
Unfixed customer orders, random order arrivals, stochastic order cycle, and nonlinear stock level increase the complexity of the model. We include ordering cost and inventory cost in the model to find the optimal order quantity so as to achieve minimum average cost on an order cycle. Inventory cost is derived based on real-time inventory level.

\section{Parameter}

AC: average cost on an order cycle

$L$ : lead time of material procurement

$h$ : holding cost per unit per time unit

$p$ : stock-out cost per time unit

$a$ : ordering cost per procurement

SS: safety stock

$X(t)$ : stock level (continuous random variable) at time $t$

$g(x, t)$ : probability density function of stock level $x$ at time $t, g(X(t)=x)$

$G(x, t)$ : cumulative distribution function of $g(x, t)$

$Y_{i}$ : customer order quantity per order, $Y_{i} \sim\left(\mu_{Z}, \sigma_{Z}^{2}\right)$, $i=1,2, \ldots$.

$Z(t)$ : accumulated customer demand at time $t$

$u(z, t)$ : probability density function of $Z$,

$N(t)$ : customer order arrivals during $[0, t]$

$T$ : order cycle between two adjacent customer order arrivals

$v(t)$ : probability density function of $T$

$R(t)$ : the probability of material arrival at time $t(t<$ $T)$

$\alpha$ : Service level.

\section{Decision Variable}

Q: order quantity (to a supplier), unit per order.

\section{Assumption}

(1) the replenishment lead time $L$ is constant

(2) in an order cycle, there is no outstanding order at $t=$ 0 . Inventory level at $t=0$ is $r+Q$.

Preliminaries. $N(t) \in N^{+}, \forall t_{1}<t_{2}, N\left(t_{1}\right) \leq N\left(t_{2}\right), N\left(t_{2}\right)-$ $N\left(t_{1}\right)$ counts the times of customer order arrival during $\left(t_{1}, t_{2}\right]$.

$\because N(0)=0$, and $N(t)$ independently increase,

$$
\begin{gathered}
P\{N(t+\Delta t)-N(t) \geq 2\}=o(\Delta t), \\
P\{N(t+\Delta t)-N(t)=1\}=\lambda \Delta t+o(\Delta t),
\end{gathered}
$$

where $o(\Delta t)$ stands for infinitesimal of higher order.

$\therefore N(t)$ is a Poisson process. For all $s, t>0, P\{N(t+s)-$ $N(s)=n\}=e^{-\lambda t}\left((\lambda t)^{n} / n !\right)$.
Proposition 1. The expected ordering cost per unit time is $a \mu_{Z} \lambda$.

Proof. During a lead time $L$, customer order arrivals are Poisson process.

Thus,

$$
\begin{aligned}
E( & Z(t)) \\
= & E\left(\sum_{i=1}^{N(t+L)-N(t)} Y_{i}\right) \\
= & \sum E(X \mid N(t+L)-N(t)=k) \\
& \times P(N(t+L)-N(t)=k) \\
= & \left.\sum \sum_{i=1}^{N(t+L)-N(t)} Y_{i} \mid N(t+L)-N(t)=k\right) \\
& \times P(N(t+L)-N(t)=k) \\
= & \sum E\left(\sum_{i=1}^{k} Y_{i}\right) P(N(t+L)-N(t)=k) \\
= & \frac{E\left(Y_{i}\right) k e^{-\lambda L}(\lambda L)^{k}}{k !}=\mu_{Z} \lambda L .
\end{aligned}
$$

$\therefore$ The expectation of customer demands required during $L$ is $\mu_{Z} \lambda L$ :

$$
\frac{a \mu_{Z} \lambda L}{L}=a \mu_{Z} \lambda
$$

Thus, we can infer that the expected ordering cost per unit time is $a \mu_{Z} \lambda$.

3.2. Optimal Policy with $r$ Determined by Service Level. In this section, reorder point is predefined by service level $\alpha$. Let $F(\cdot)$ represent the c.d.f. of the standard normal distribution with mean 0 and standard deviation 1 . Define $w$ as the solution to $F(w)=\alpha$ and $r$ as the reorder point for a cycle service level of $\alpha[30,31]$.

The order arrivals conform to Poisson process while the customer demand $Z$ conforms to normal distribution, $Z \sim$ $\left(\mu_{Z}, \sigma_{Z}^{2}\right)$. Thus the safety stock and reorder point are still determined by the following equations:

$$
\begin{gathered}
\mathrm{SS}=w \sqrt{\mu_{L} \sigma_{Z}^{2}+\mu_{Z}^{2} \sigma_{L}^{2}} \\
r=\mathrm{SS}+L \mu_{Z}=w \sqrt{L} \sigma_{Z}+L \mu_{Z},
\end{gathered}
$$

problem formulation: $\min \quad E(\mathrm{AC})$,

$$
\text { s.t. } \quad r+Q \leq m \text {. }
$$

According to Federgruen and Zheng [2], Hadley and Whitin [1], and Sivazlian [32], in the steady state, IL $=$ IP $-D$. IP denotes inventory position and IL inventory level. In this paper, we compute inventory cost based on inventory level. 
Thus according to infinitesimal method, during a unit time $[t, t+d t]$, the expected inventory cost is

$$
\begin{gathered}
d E\left(C_{I}\right)=\left(h \int_{0}^{r+Q} x g(x, t) d x+p \int_{-\infty}^{0} x g(x, t) d x\right) d t \\
E\left(C_{I}\right)=h \int_{0}^{T} \int_{0}^{r+Q} x g(x, t) d x d t \\
+p \int_{0}^{T} \int_{-\infty}^{0} x g(x, t) d x d t .
\end{gathered}
$$

The average cost on an expected order cycle is

$$
\begin{aligned}
E(\mathrm{AC})= & \frac{1}{\bar{T}}\left(h \int_{0}^{\bar{T}} \int_{0}^{r+Q} x g(x, t) d x d t\right. \\
& \left.+p \int_{0}^{\bar{T}} \int_{-\infty}^{0} x g(x, t) d x d t\right)+a \frac{\lambda \mu_{Z}}{Q} \\
\frac{\partial E(\mathrm{AC})}{\partial Q}= & \frac{k}{\bar{T}}+\frac{h}{\bar{T}} \frac{\partial \int_{0}^{\bar{T}} \int_{0}^{r+Q} x g(x, t) d x d t}{\partial Q}-\frac{a \lambda \mu_{Z}}{Q^{2}} \\
= & \frac{h(r+Q)}{\bar{T}} \int_{0}^{\bar{T}} g(r+Q, t) d t-\frac{a \lambda \mu_{Z}}{Q^{2}} \\
\frac{\partial^{2} E(\mathrm{AC})}{\partial Q^{2}}= & \frac{h(r+Q)}{\bar{T}} \frac{\partial \int_{0}^{\bar{T}} g(r+Q, t) d t}{\partial Q} \\
& +\frac{h}{\bar{T}} \int_{0}^{\bar{T}} g(r+Q, t) d t+\frac{2 a \lambda \mu_{Z}}{Q^{3}} .
\end{aligned}
$$

$\because \partial^{2} E(\mathrm{AC}) / \partial Q^{2}>0, E(T C)$ is the convex function of $Q$, the minimum cost exists.

From $(Q, r)$ model, $Z(T)=Q$, and $Z\left(t_{1}\right), Z\left(t_{2}\right)-$ $Z\left(t_{1}\right), Z\left(t_{3}\right)-Z\left(t_{2}\right), \ldots, Z\left(t_{n}\right)-Z\left(t_{n-1}\right)$ is independent,

$$
\begin{aligned}
\forall t & <T, u_{Z(T)=Q}(z, t) \\
& =u(Z(t)=z \mid Z(T)=Q) \\
& =\frac{u(Z(t)=z) u(Z(T-t)=Q-z)}{u(Z(T)=Q)} \\
& =\frac{u(z, t) u(Q-z, T-t)}{u(Q, T)} .
\end{aligned}
$$

Notice that $z=r+Q-x$ when $Q$ arrives; otherwise $z=r-x$

$$
\begin{aligned}
\forall t<T, g(x, t)= & R u_{Z(T)=Q}(r+Q-x, t) \\
& +(1-R) u_{Z(T)=Q}(r-x, t) .
\end{aligned}
$$

$\therefore g(x, t)$ can be derived from $u(z, t)$.

Assume $R=1$

$$
\therefore g(x, t)=\frac{u(r+Q-x, t) u(x-r, T-t)}{u(Q, T)} .
$$

According to Lagrange mean value theorem. $\because g(x, t)$ is continuous on interval $[0, T]$,

$$
\begin{gathered}
\therefore \exists \xi \in[0, T], \text { s.t. } \int_{0}^{T} g(r+Q, t) d t=g(r+Q, \xi) T \\
\frac{\partial E(T C)}{\partial Q}=0, \\
\int_{0}^{T} g(r+Q, t) d t=\operatorname{Pr}\{X(t)=r+Q, 0 \leq t \leq T\} .
\end{gathered}
$$

According to the assumption $t=0, X(t)=r+Q$,

$$
\begin{gathered}
\therefore g(r+Q, \xi)=\frac{u(0,0) u(Q, T)}{u(Q, T)}=u(0,0) \\
\frac{\partial E(T C)}{\partial Q}=0, \quad h(r+Q) \theta=\frac{a \lambda \mu_{Z}}{Q^{2}} \\
h \theta(r+Q) Q^{2}=a \mu_{Z} \lambda .
\end{gathered}
$$

To find solutions to this cubic equation, assume

$$
\begin{aligned}
A=(h \theta r)^{2}, & B=9 h \theta a \lambda \mu_{Z}, \quad C=3 h \theta r a \lambda \mu_{Z} \\
B^{2}-4 \mathrm{AC}= & 81\left(h \theta a \lambda \mu_{Z}\right)^{2}-12(h \theta r)^{3} a \lambda \mu_{Z} \\
= & (h \theta)^{2} a \lambda \mu_{Z}\left(81 a \lambda \mu_{Z}-12 h \theta r^{3}\right) \\
\widetilde{Q} & =\frac{-h \theta r-\left(\sqrt[3]{H_{1}}+\sqrt[3]{H_{2}}\right)}{3 h \theta} \\
= & \frac{-r}{3}-\frac{\sqrt[3]{H_{1}}+\sqrt[3]{H_{2}}}{3 h \theta} \\
= & \frac{-r}{3}-\frac{\sqrt[3]{H_{1}}+\sqrt[3]{H_{2}}}{3 h \theta} \\
H_{1,2}= & (h \theta r)^{3}+3 h \theta \frac{-B \pm \sqrt{B^{2}-4 \mathrm{AC}}}{2} \\
= & (h \theta r)^{3}+3 h \theta \frac{-B \pm \sqrt{B^{2}-4 \mathrm{AC}}}{2} .
\end{aligned}
$$

Consider the constraints $r+Q \leq m$.

When $r+Q$ reaches $m$,

$$
\begin{gathered}
h \theta(r+Q) Q^{2}=a \mu_{Z} \lambda \leq h \theta m Q^{2}, \\
h \theta m Q^{2} \geq a \mu_{Z} \lambda .
\end{gathered}
$$

Thus $Q^{2} \geq a \mu_{Z} \lambda / m h \theta$ :

$$
m-r \geq Q \geq \sqrt{\frac{a \mu_{Z} \lambda}{m h \theta}} .
$$

From (16), $\widetilde{Q}$ is the extreme point of (8). However, it still needs to be compared with the two end points in (18) to obtain the minimum of expected average cost. 
Thus

$$
Q^{*}=\arg \min \left\{\mathrm{AC}(q) \mid q=\widetilde{Q}, m-r, \sqrt{\frac{a \mu_{Z} \lambda}{m h \theta}}\right\} \text {. }
$$

In this section, we predefine $r$ by service level and obtain the expression of optimal $Q$. In the following part, we will relax the policy and derive the optimum of $Q$ and $r$ with consideration of the p.d.f of $T$.

3.3. Optimal Policy on $Q$ and $r$. If we consider the random variability of $T$, then the average cost $E(A C)$ in (5) is

$E(\mathrm{AC})$

$$
\begin{aligned}
=\int_{0}^{\infty} \frac{1}{T} & \left(h \int_{0}^{T} \int_{0}^{r+Q} x g(x, \tau) d x d \tau\right. \\
& \left.+p \int_{0}^{T} \int_{-\infty}^{0} x g(x, \tau) d x d \tau\right) v(t) d t+a \frac{\lambda \mu_{Z}}{Q} .
\end{aligned}
$$

Proposition 2. The p.d.f of $T$ is subject to $N\left(\mu_{Z}, \sigma_{Z}^{2}\right)$. t\}

$v(t)$ is the p.d.f of order cycle, r.v. T, $\int_{-\infty}^{t} v(t) d t=\operatorname{Pr}\{T \leq$

Through the following generation, $v(t)$ is obtained

$$
\begin{aligned}
& V_{T \mid t_{n}}\left(t \mid z\left(t_{n}\right)\right) \\
& =\operatorname{Pr}\left\{T \leq t_{n} \mid t_{n}=t_{n}\right\} \\
& =\operatorname{Pr}\left\{Z\left(t_{n}+\Delta t\right)-Z(t)\right. \\
& \left.\quad=i_{n+1}-i_{n} \mid Z\left(t_{n-1}\right)-Z(0)=i_{n-1}\right\} \\
& =\operatorname{Pr}\left\{Z\left(t_{n+1}\right)-Z\left(t_{n}\right)\right. \\
& \left.\quad=i_{n+1}-i_{n} \mid Z\left(t_{n-1}\right)-Z(0)=i_{n-1}\right\} \\
& =\operatorname{Pr}\left\{Z\left(t_{n+1}\right)-Z\left(t_{n}\right)=i_{n+1}-i_{n}\right\} \\
& =\int_{-\infty}^{t} \frac{1}{\sqrt{2 \pi} \sigma_{Z}} \exp \left(-\frac{\left(t-\mu_{Z}\right)^{2}}{2 \sigma_{Z}^{2}}\right) d t .
\end{aligned}
$$

The conditional p.d.f of $V_{T \mid t_{n}}\left(t \mid z\left(t_{n}\right)\right)$ is

$$
v_{T \mid t_{n}}\left(t \mid z\left(t_{n}\right)\right)=\frac{1}{\sqrt{2 \pi} \sigma_{Z}} \exp \left(-\frac{\left(t-\mu_{Z}\right)^{2}}{2 \sigma_{Z}^{2}}\right) .
$$

The joint probability function of $T, t_{n}$ is

$$
v\left(t, t_{n}\right)=\frac{1}{\sqrt{2 \pi} \sigma_{Z}} \exp \left(-\frac{\left(t-\mu_{Z}\right)^{2}}{2 \sigma_{Z}^{2}}\right) f_{t_{n}}\left(t_{n}\right) .
$$

Integrate on $t_{n}$ to get p.d.f of $T$

$$
\begin{aligned}
v(t) & =\int_{0}^{\infty} \frac{1}{\sqrt{2 \pi} \sigma_{Z}} \exp \left(-\frac{\left(t-\mu_{Z}\right)^{2}}{2 \sigma_{Z}^{2}}\right) f_{t_{n}}\left(t_{n}\right) d t_{n} \\
& =\frac{1}{\sqrt{2 \pi} \sigma_{Z}} \exp \left(-\frac{\left(t-\mu_{Z}\right)^{2}}{2 \sigma_{Z}^{2}}\right) \int_{0}^{\infty} f_{t_{n}}\left(t_{n}\right) d t_{n} \\
& =\frac{1}{\sqrt{2 \pi} \sigma_{Z}} \exp \left(-\frac{\left(t-\mu_{Z}\right)^{2}}{2 \sigma_{Z}^{2}}\right) .
\end{aligned}
$$

Thus the proposition is proved.
Thus, $E(\mathrm{AC})$ in (20) can be written as

$E(\mathrm{AC})$

$$
\begin{aligned}
=\int_{0}^{\infty} \frac{1}{t}\left(h \int_{0}^{t} \int_{0}^{r+Q} x g(x, \tau) d x d \tau\right. \\
\left.+p \int_{0}^{t} \int_{-\infty}^{0} x g(x, \tau) d x d \tau\right) \frac{1}{\sqrt{2 \pi} \sigma_{Z}} \\
\quad \times \exp \left(-\frac{\left(t-\mu_{Z}\right)^{2}}{2 \sigma_{Z}^{2}}\right) d t+a \frac{\lambda \mu_{Z}}{Q}
\end{aligned}
$$

Problem formulation: $\min \quad E(\mathrm{AC})$

$$
\begin{array}{ll}
\text { s.t. } & r+Q \leq m \\
& r \geq 0 \\
& Q>0 .
\end{array}
$$

Traditional optimization method is not easy to find optimum $Q$ for (19) due to its complexity. Thus we will use genetic algorithm to reach the optimums. $a, p, h$, and $\lambda$ are selected as input parameters. $E(A C)$ in (25) is regarded as the objective function. The simulation processes can be illustrated as follows (see Figure 3).

3.4. Extension of the Model. The previous model can be extended for discrete customer demands (see Figure 4).

Assume probability distribution function of demands: $P(Z(t)=z)$.

According to the homogeneity of Poisson process

$$
\begin{aligned}
& P(Z(t)=n \mid Z(T)=Q) \\
& =\frac{P(Z(t)=n, Z(T-t)=Q-n)}{P(Z(T)=Q)} \\
& =\frac{P(Z(t)=n) \cdot P(Z(T-t)=Q-n)}{P(Z(T)=Q)} \\
& \operatorname{Pr}(z, t) \\
& =R \operatorname{Pr}(Z(t)=Q+r-x \mid Z(t)=Q) \\
& \quad+(1-R) \operatorname{Pr}(Z(t)(r-x) \mid Z(T)=Q) \\
& E\left(C_{I}\right) \quad \int_{\tau=0}^{t} \sum_{z=1}^{+\infty} h z \operatorname{Pr}(z, \tau) d \tau+\int_{\tau=0}^{t} \sum_{z=-\infty}^{-1} p z \operatorname{Pr}(z, \tau) d \tau \\
& \quad(\mathrm{AC}) \\
& \quad=\int_{0}^{\infty} \frac{1}{t}\left(\int_{i=0}^{t} \sum_{z=1}^{+\infty} h z \operatorname{Pr}(z, \tau) d \tau\right. \\
& \left.\quad+\int_{t=0}^{t} \sum_{z=-\infty}^{-1} p z \operatorname{Pr}(z, \tau) d \tau\right) v(t) d t+\frac{a \lambda \mu_{Z}}{Q} .
\end{aligned}
$$

We will also adopt genetic algorithm to obtain the optimal $Q$ and $r$ for discrete demands. The procedures are the same as those in Section 3.2. Numerical analysis will be conducted in Section 4. 


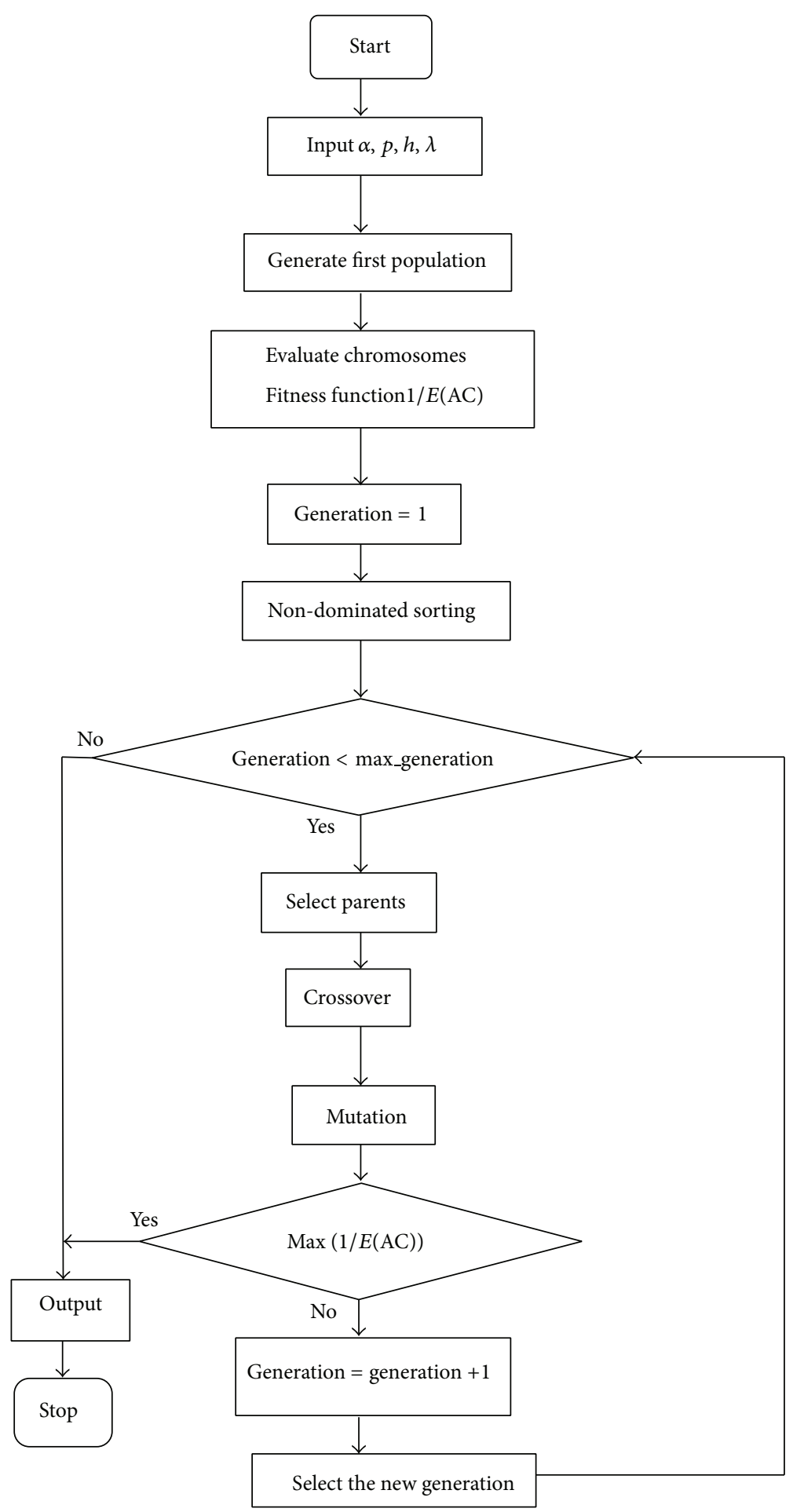

FIGURE 3: The procedures of genetic algorithm in finding $\min (E(A C))$.

\section{Numerical Analysis and Insights}

To verify the solution, numerical analysis is given with real data obtained from the health care center from January to March, 2013.

Table 1 shows the parameters of the mathematical models. Table 2 shows optimal $Q$ when $r$ is determined by service level. Table 3 reflects the optimal results of genetic algorithm while Table 4 shows the optimization for discrete customer demands.

\subsection{Numerical Studies. Assume $\lambda=1, m=120$.}

Table 5 is the policy determined by human being in real practice. The inventory manager of the center usually counts on his previous experience to propose the order quantity, while our optimization system is developed on account of 


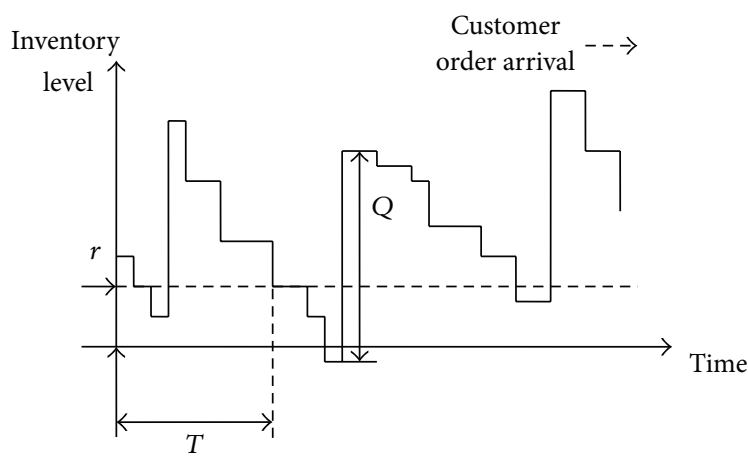

FIGURE 4: Inventory variation on discrete customer demands.

TABle 1: Parameters of the model

\begin{tabular}{lcccccc}
\hline & $a$ & $h$ & $p$ & $L$ & $\alpha$ & $\mu_{z}$ \\
\hline Wheelchair Raincoat (one piece) & 40 & 20 & 8 & 1.5 & 1 & 30 \\
Safety Jumpsuit & 45 & 24 & 9 & 1 & 0.95 & 33 \\
Apron & 42 & 22 & 8 & 2 & 0.85 & 15 \\
\hline
\end{tabular}

TABLE 2: Optimal policy of $Q$ in Section 3.1.

\begin{tabular}{lccc}
\hline & $r$ & $Q$ & $E(\mathrm{AC})$ \\
\hline Wheelchair raincoat & 9.50 & 72.3 & 55.6 \\
Safety jumpsuit & 5.95 & 75.2 & 68.5 \\
Apron & 6.85 & 68.7 & 32.1 \\
\hline
\end{tabular}

TABLE 3: Optimal policy of $Q$ and $r$ in Section 3.2 (genetic algorithm).

\begin{tabular}{lccc}
\hline & $r$ & $Q$ & $E(\mathrm{AC})$ \\
\hline Wheelchair raincoat & 10.21 & 78.8 & 63.6 \\
Safety jumpsuit & 6.83 & 88.3 & 79.5 \\
Apron & 7.36 & 71.2 & 36.7 \\
\hline
\end{tabular}

mathematical generation. Compared results in Tables 3 and 5 , and difference can be found between real practice and optimization system. The expected average cost is generally reduced at around 17 20\% with the models introduced in the paper. The inventory manager is usually conservative and reorder point is higher than optimal $r$. When customer demands are considered as discrete in Table 4, the cost is also less than that of real practice. The optimization models provide referenced $r$ and $Q$ for the inventory manager to achieve cost minimization.

4.2. Insights Analysis. Sensitivity analysis is conducted with variation of the input parameters in genetic algorithm to analyze their effect on the optimal results. Take the product of wheelchair raincoat for example.

The increase of $a$ increases the ordering cost and thus correspondingly has an increasing effect on the average cost (see Table 6). We find that $Q$ derived by genetic algorithm also increases. It can be explained that the larger $Q$ is, the less the ordering cost on each unit increases.
TABLE 4: Optimal policy for discrete customer demands.

\begin{tabular}{lccc}
\hline & $r$ & $Q$ & $E(\mathrm{AC})$ \\
\hline Wheelchair raincoat & 11 & 79 & 65.1 \\
Safety jumpsuit & 7 & 88 & 80.5 \\
Apron & 6 & 70 & 38.1 \\
\hline
\end{tabular}

TABLE 5: Business practitioner's policy.

\begin{tabular}{lccc}
\hline & $r$ & $Q$ & $E(\mathrm{AC})$ \\
\hline Wheelchair raincoat & 13 & 80 & 77.3 \\
Safety jumpsuit & 7 & 75 & 82.2 \\
Apron & 8 & 60 & 42.8 \\
\hline
\end{tabular}

TABLE 6: The Effect of variation of $a$ on $Q$ and $r$ in Section 3.2.

\begin{tabular}{lccc}
\hline$a$ & $r$ & $Q$ & $E(\mathrm{AC})$ \\
\hline 40 & 10.21 & 78.8 & 63.6 \\
50 & 11.92 & 80.2 & 65.5 \\
60 & 13.23 & 81.9 & 66.3 \\
70 & 14.91 & 82.1 & 67.6 \\
80 & 16.01 & 83.0 & 68.1 \\
90 & 17.53 & 84.9 & 69.3 \\
\hline
\end{tabular}

TABLE 7: The effect of variation of $\lambda$ on $Q$ and $r$ in Section 3.2.

\begin{tabular}{lccc}
\hline$\lambda$ & $r$ & $Q$ & $E(\mathrm{AC})$ \\
\hline 1 & 10.21 & 78.8 & 63.6 \\
1.2 & 10.52 & 79.3 & 64.2 \\
1.4 & 11.32 & 80.6 & 65.3 \\
1.6 & 12.13 & 81.2 & 66.2 \\
1.8 & 12.97 & 82.4 & 67.5 \\
2.0 & 13.78 & 83.3 & 68.7 \\
\hline
\end{tabular}

From Table 7, the increase in $\lambda$ leads to increase in $r$ and $Q$. The larger $\lambda$ means customer demands per unit time increases. To avoid the occurrence of stock-out, $r$ and $Q$ both increase. Thus the average cost increases.

From Table 8, the increase in $p$ brings about increases in $r$ and average cost. When stock-out cost per unit time becomes larger, the shortage cost adds on. To avoid stock-out situation, the level of reorder point has to be raised.

From Table 9, the increase of $h$ increase inventory cost thus correspondingly has an increasing effect on the average cost. $Q$ derived by genetic algorithm also increases. It can be explained that larger $Q$ offsets the increase in the inventory cost on each unit.

\section{Conclusion and Future Work}

An inventory control system tells us how much to order and when to place the order. Large amounts of research have been made on inventory policy and lots of optimal proposals have been raised for inventory models; however, investigation on the situation of limited inventory capacity is not much, especially under a stochastic environment. In this paper, how 
TABLE 8: The effect of variation of $p$ on $Q$ and $r$ in Section 3.2.

\begin{tabular}{lccc}
\hline$p$ & $r$ & $Q$ & $E(\mathrm{AC})$ \\
\hline 20 & 10.21 & 78.8 & 63.6 \\
21 & 12.33 & 76.1 & 65.1 \\
22 & 13.72 & 75.2 & 66.9 \\
23 & 14.81 & 73.8 & 68.0 \\
24 & 16.02 & 72.5 & 69.2 \\
25 & 17.13 & 71.3 & 70.1 \\
\hline
\end{tabular}

TABLE 9: The effect of variation of $h$ on $Q$ and $r$ in Section 3.2.

\begin{tabular}{lccc}
\hline$h$ & $r$ & $Q$ & $E(\mathrm{AC})$ \\
\hline 8 & 10.21 & 78.8 & 63.6 \\
9 & 9.82 & 80.6 & 64.7 \\
10 & 8.51 & 81.8 & 65.9 \\
11 & 7.33 & 83.1 & 67.1 \\
12 & 6.63 & 84.3 & 68.3 \\
13 & 5.17 & 85.9 & 69.0 \\
\hline
\end{tabular}

to find an optimal order quantity under certain constraints to minimize average cost including inventory and ordering cost is the key issue. We propose an inventory system with restriction on capacity for the case of health care center based on $(Q, r)$ policy. Firstly, we derive the expression of optimal order quantity with polynomial time computational complexity, provided reorder point determined by service level. Secondly, without service level definition, genetic algorithm is proposed to generate optimal $Q$ and $r$ for the capacitated inventory system. Thirdly, we derive a model extension on discrete demands. With comparisons to the results of experiencebased decision on $Q$ and $r$, the optimal policies we provided lead to an average cost reduction by $17 \sim 20 \%$.

In this paper, we discuss the capacitated single item inventory system. However, the resource can be commonly shared across different items, rather than exclusively used in part by a specified item. Then, an optimization problem for multi-item $(Q, r)$ policies with a constraint of such a resource becomes more complex and will be a direction for future research.

\section{Conflict of Interests}

The authors declare that there is no conflict of interests regarding the publication of this paper.

\section{References}

[1] G. Hadley and T. M. Whitin, Analysis of Inventory Systems, Prentice Hall, Englewood Cliffs, NJ, USA, 1963.

[2] A. Federgruen and Y. Zheng, "Efficient algorithm for computing an optimal ( $\mathrm{r}, \mathrm{Q})$ policy in continuous review stochastic inventory systems," Operations Research, vol. 40, no. 4, pp. 808813, 1992.

[3] R. Forsberg, "Exact evaluation of $(R, Q)$-policies for two-level inventory systems with Poisson demand," European Journal of Operational Research, vol. 96, no. 1, pp. 130-138, 1997.
[4] A. H. Lau, H. S. Lau, and L. W. Robinson, "Convenient expressions for computing the exact annual cost of a continuousreview (Q, R) system with backordering," Journal of the Operational Research Society, vol. 53, no. 6, pp. 655-663, 2002.

[5] Y. Zheng, "On properties of stochastic inventory systems," Management Science, vol. 38, no. 1, pp. 87-103, 1992.

[6] J. R. Bradley and P. W. Glynn, "Managing capacity and inventory jointly in manufacturing systems," Management Science, vol. 48, no. 2, pp. 273-288, 2002.

[7] R. P. Parker and R. Kapuscinski, "Optimal policies for a capacitated two-echelon inventory system," Operations Research, vol. 52, no. 5, pp. 739-755, 2004.

[8] Ö. Özer and W. Wei, "Inventory control with limited capacity and advance demand information," Operations Research, vol. 52, no. 6, pp. 988-1000, 2004.

[9] E. L. Plambeck, "Asymptotically optimal control for an assemble-to-order system with capacitated component production and fixed transport costs," Operations Research, vol. 56, no. 5, pp. 1158-1171, 2008.

[10] S. J. Erlebacher, "Optimal and heuristic solutions for the multiitem newsvendor problem with a single capacity constraint," Production and Operations Management, vol. 9, no. 3, pp. 303318, 2000.

[11] H. Lau and A. H. Lau, "The newsstand problem: a capacitated multiple-product single-period inventory problem," European Journal of Operational Research, vol. 94, no. 1, pp. 29-42, 1996.

[12] E. A. Silver, D. F. Pyke, and R. Peterson, Inventory Management and Production Planning and Scheduling, John Wiley, New York, NY, USA, 1998.

[13] H. Scarf, A Survey of Analytic Techniques in Inventory Theory, Stanford University Press, Stanford, Calif, USA, 1963.

[14] J. Song and P. Zipkin, "Inventory control in a fluctuating demand environment," Operations Research, vol. 41, no. 2, pp. 351-370, 1993.

[15] S. Browne and P. Zipkin, "Inventory models with continuous stochastic demands," Annals of Applied Probability, vol. 1, pp. 419-435, 1991.

[16] E. A. Silver, "Operations research in inventory management: a review and critique," Operations Research, vol. 29, no. 4, pp. 628645, 1981.

[17] S. K. Goyal and A. T. Satir, "Joint replenishment inventory control: deterministic and stochastic models," European Journal of Operational Research, vol. 38, no. 1, pp. 2-13, 1989.

[18] A. Eynan and D. H. Kropp, "Effective and simple EOQlike solutions for stochastic demand periodic review systems," European Journal of Operational Research, vol. 180, no. 3, pp. 1135-1143, 2007.

[19] S. A. Tarim and B. G. Kingsman, "Modelling and computing $(\mathrm{Rn}, \mathrm{Sn})$ policies for inventory systems with non-stationary stochastic demand," European Journal of Operational Research, vol. 174, no. 1, pp. 581-599, 2006.

[20] M. Ben-Daya and S. M. Noman, "Integrated inventory and inspection policies for stochastic demand," European Journal of Operational Research, vol. 185, no. 1, pp. 159-169, 2008.

[21] J. S. Song, H. Q. Zhang, Y. M. Hou, and M. Z. Wang, "The effect of lead time and demand uncertainties in $(r, q)$ inventory systems," Operations Research, vol. 58, no. 1, pp. 68-80, 2010.

[22] E. Berk and Ü. Gürler, "Analysis of the $(Q, r)$ inventory model for perishables with positive lead times and lost sales," Operations Research, vol. 56, no. 5, pp. 1238-1246, 2008. 
[23] S. Axsäter, "Exact and approximate evaluation of batchordering policies for two-level inventory systems," Operations Research, vol. 41, no. 4, pp. 777-785, 1993.

[24] S. Axsäter, "Evaluation of installation stock based $(R, Q)$ policies for two-level inventory systems with poisson demand," Operations Research, vol. 46, no. 3, pp. 135-145, 1998.

[25] S. Axsäter, "Exact analysis of continuous review $(R, Q)$-policies in two-echelon inventory systems with compound Poisson demand," Operations Research, vol. 48, no. 5, pp. 686-696, 2000.

[26] L. Yang, J. Yang, G. Yu, and H. Q. Zhang, "Near-optimal (r,Q) policies for a two-stage serial inventory system with poisson demand," International Journal of Production Economics, vol. 133, no. 2, pp. 728-735, 2011.

[27] D. E. Platt, L. W. Robinson, and R. B. Freund, "Tractable $(Q, R)$ heuristic models for constrained service levels," Management Science, vol. 43, no. 7, pp. 951-965, 1997.

[28] G. Gallego, "New bounds and heuristics for (Q, r) policies," Management Science, vol. 44, no. 2, pp. 219-233, 1998.

[29] P. Alstr and P. Alstrøm, "Numerical computation of inventory policies, based on the EOQ/ $\sigma \mathrm{x}$ value for order-point systems," International Journal of Production Economics, vol. 71, no. 1-3, pp. 235-245, 2001.

[30] E. A. Silver and R. Peterson, Decision Systems for Inventory Management and Production Planning, John Wiley \& Sons, New York, NY, USA, 2nd edition, 1985.

[31] S. Chopra, G. Reinhardt, and M. Dada, "The effect of lead time uncertainty on safety stocks," Decision Sciences, vol. 35, no. 1, pp. 1-24, 2004.

[32] B. D. Sivazlian, "A continuous-review $(s, S)$ inventory system with arbitrary interarrival distribution between unit demand," Operations Research, vol. 22, no. 1, pp. 65-71, 1974. 


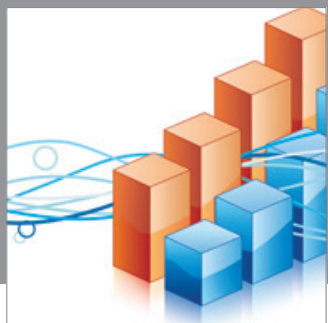

Advances in

Operations Research

mansans

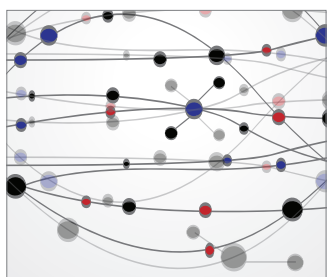

The Scientific World Journal
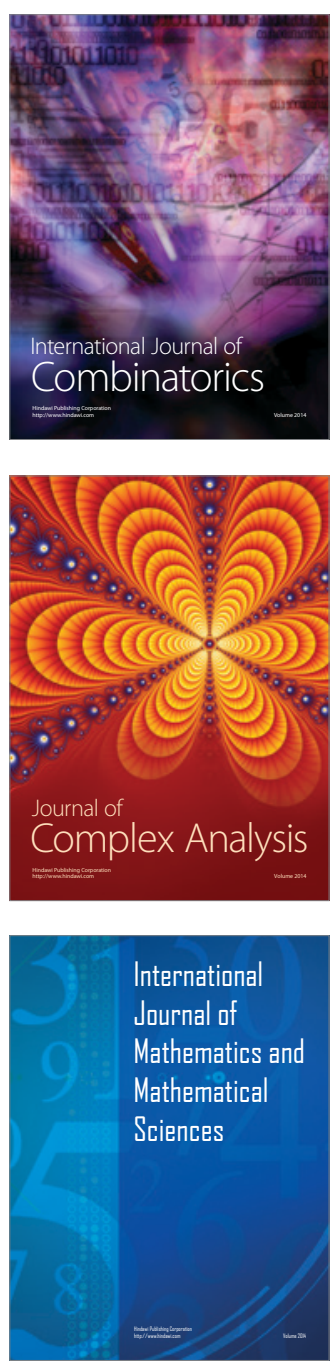
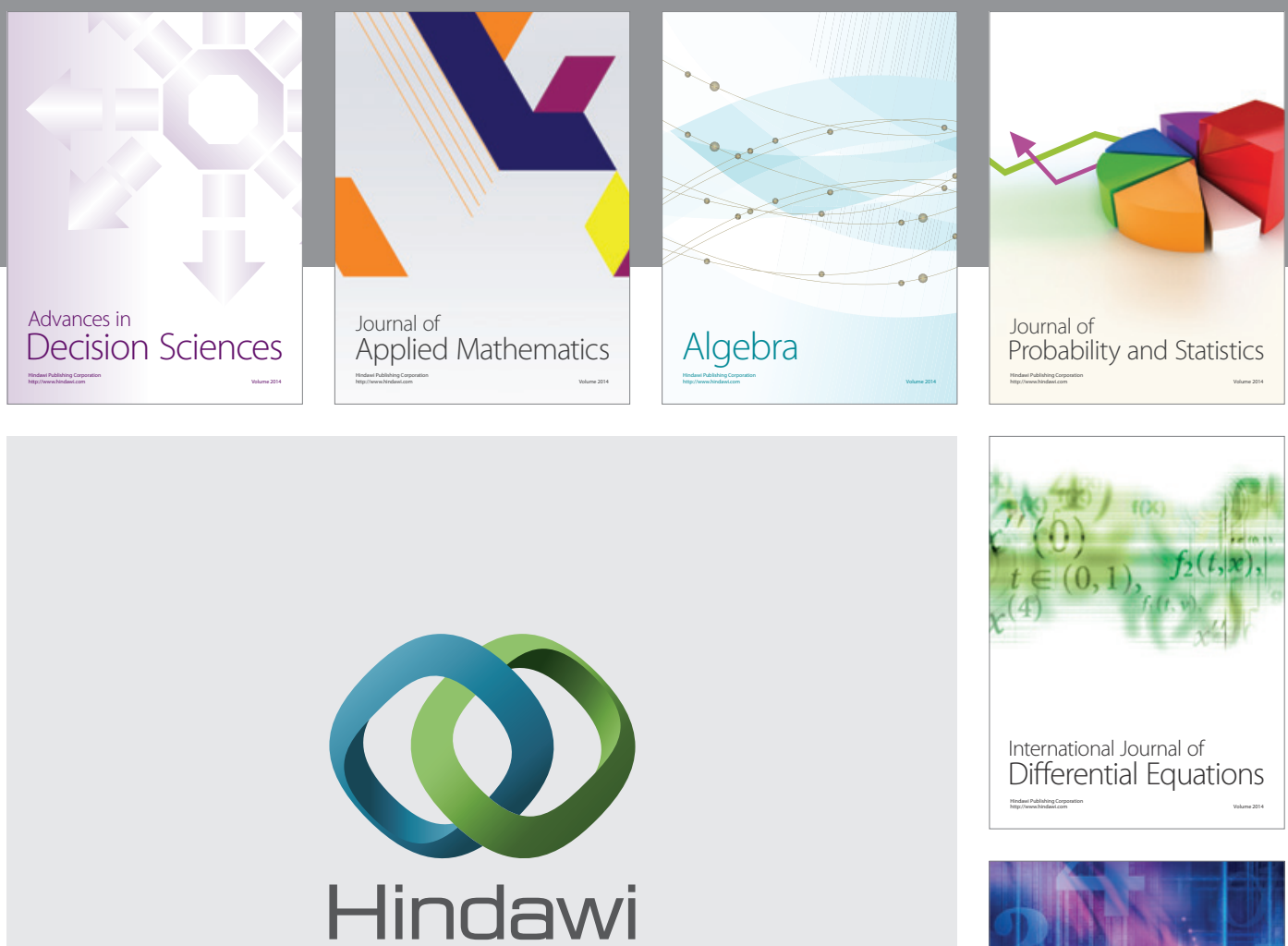

Submit your manuscripts at http://www.hindawi.com
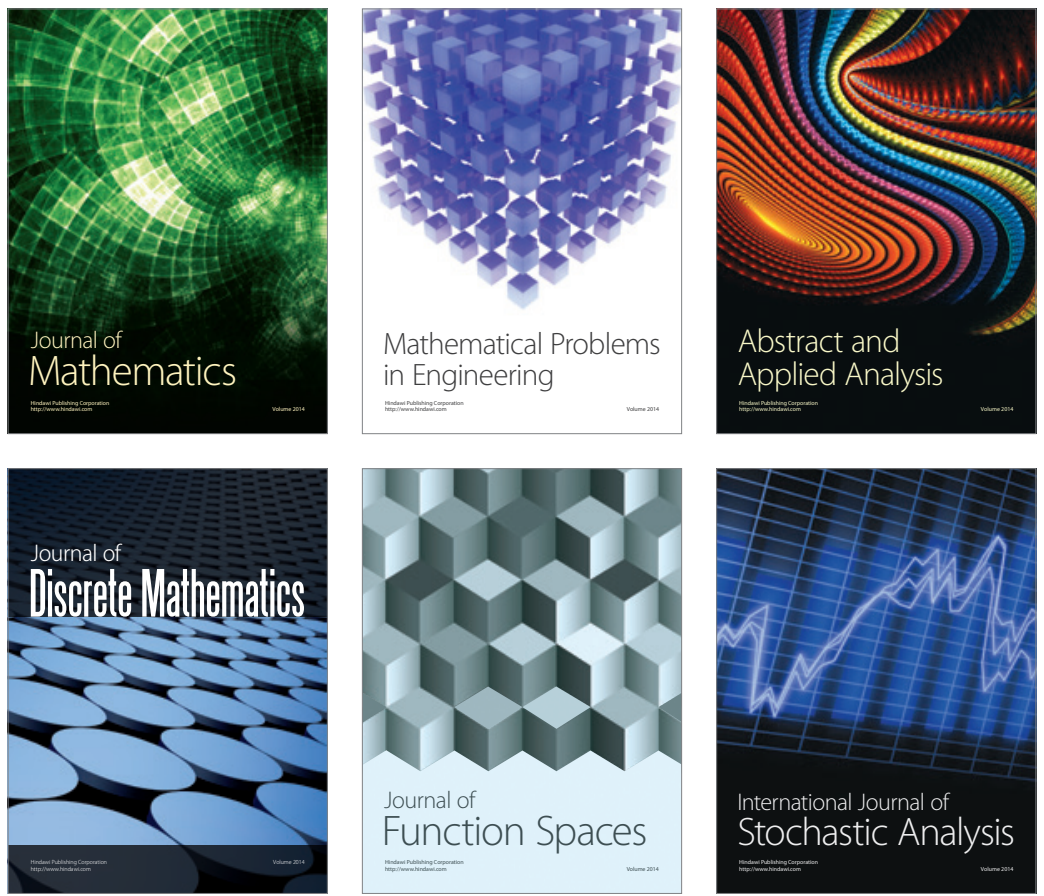

Journal of

Function Spaces

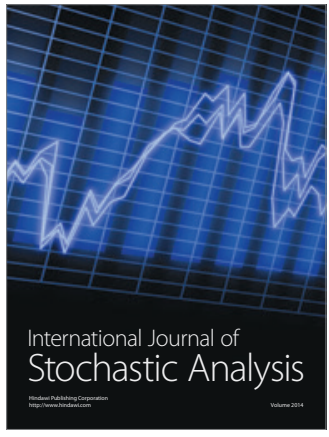

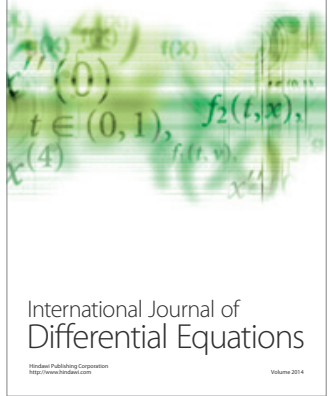
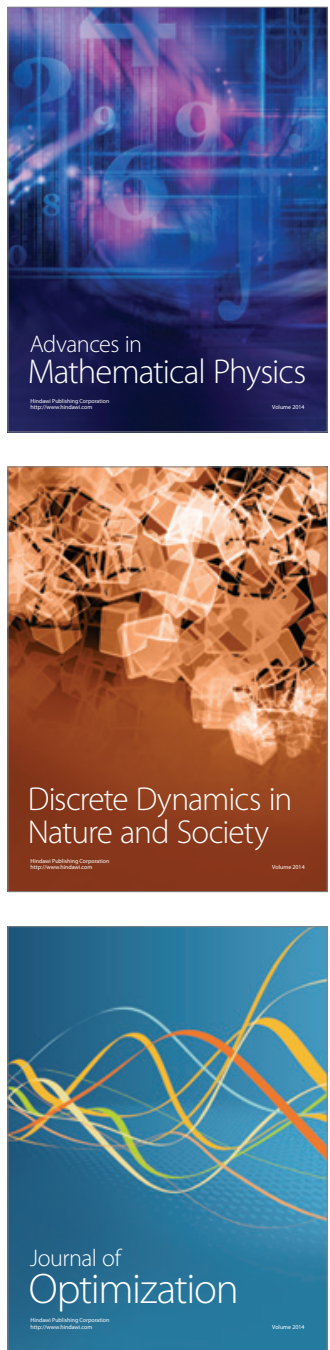